\title{
Correlation between Residual Renal Function and Hypertension in Regular Haemodialysis Patients
}

\author{
Said S. A. Khamis ${ }^{1}$, Yassein Salah1, Nahla El-Ghalban'², Hany S. Elbarbary ${ }^{1}$ \\ ${ }^{1}$ Internal Medicine Department and Nephrology Unit, College of Medicine, Menoufia University, Al Minufya, Egypt \\ ${ }^{2}$ Shebin El Kom Teaching Hospital, Menoufia, Egypt \\ Email: *drnahlayassin@gmail.com, helbarbary@kfu.edu.sa
}

How to cite this paper: Khamis, S.S.A. Salah, Y., El-Ghalban, N. and Elbarbary, H.S. (2020) Correlation between Residual Renal Function and Hypertension in Regular Haemodialysis Patients. Open Journal of Nephrology, 10, 245-253.

https://doi.org/10.4236/ojneph.2020.103024

Received: July 20, 2020

Accepted: September 5, 2020

Published: September 8, 2020

Copyright $\odot 2020$ by author(s) and Scientific Research Publishing Inc. This work is licensed under the Creative Commons Attribution International License (CC BY 4.0).

http://creativecommons.org/licenses/by/4.0/

\begin{abstract}
Objective: To evaluate the correlation between residual renal function and hypertension in regular haemodialysis patients. Background: Initiating chronic dialysis treatment gives end-stage renal disease patients a new lease on life. However, the annual mortality rate in dialysis patients is $\sim 20 \%$ and quality of life is substantially reduced. Patients and Methods: This study was carried out on a reasonable number of subjects on regular haemodialysis divided into two groups. All were given informed consent and, the study was approved by the ethics committee of Menoufia University. Results: There was significant relation between presence of residual renal function and hypertension in patients with ESRD on regular haemodialysis, but the relation between residual renal function and control of hypertension is not statistically significant. $40 \%$ of group 1 were hypertensive, $66.7 \%$ of group 2 patients were hypertensive, the interdialytic weight gain mean was 1.42 in group 1 and 2.37 in group 2. Control of hypertension was achieved in $63.6 \%$ of group 1 patients by one drug, $27.3 \%$ patients by 2 drugs; however $9.1 \%$ of patients need 3 drugs to control their blood pressure, while in group $240 \%$ of patients were controlled by one drug, $45 \%$ with 2 drugs and $15 \%$ need 3 drugs to control blood pressure. Conclusion: There is significant relation between presence of residual renal function and hypertension in patients with ESRD on regular haemodialysis, but the relation between residual renal function and control of hypertension is not statistically significant.
\end{abstract}

\section{Keywords}

Hypertension, Regular Haemodialysis, Residual Renal Function 


\section{Introduction}

Initiating chronic dialysis treatment gives end-stage renal disease patients a new lease on life. However, the annual mortality rate in dialysis patients is $\sim 20 \%$ and quality of life is substantially reduced [1].

Observational studies have shown that preservation of residual renal function [RRF] in dialysis patients is a prognostic and independent factor in patient survival and quality of life [2], also when RRF is almost completely lost. A higher dialysis dose cannot compensate for declining RRF. The increased benefit of RRF compared to dialysis clearance is likely attributable to a better water and salt balance, the renal ability to clear and metabolize various substances including middle-sized molecules such as $b$-2-microglobulin and protein-bound substances as well as the endocrine functions of the kidneys.

There is an increased focus on preserving RRF in dialysis patients [3].

In addition to providing small solute clearance, RKF continues to maintain important metabolic, hemodynamic, and endocrine functions, and plays a crucial role in maintaining the overall cardiovascular health, nutritional status, mineral metabolism balance and well-being of patients undergoing dialysis [4].

RRF remains important even after the beginning of dialysis. RRF contributes significantly to the overall health and well-being of patients on dialysis [5]. It plays an important role in maintaining fluid balance, phosphorus control, nutrition, and removal of middle molecular uremic toxins and shows inverse relationships with valvular calcification and cardiac hypertrophy in patients on dialysis. Decline in RRF also contributes significantly to anemia, inflammation, and malnutrition in patients on dialysis [6].

Whereas the role of RRF for survival is well recognized in the peritoneal dialysis population, it has not received much attention in the hemodialysis population. In a recent study by [7], there were strong data showing that RRF contributes significantly to improved outcomes in hemodialysis patients and that efforts to preserve it are warranted. However, comparative outcome studies should be controlled for the presence of RRF.

The rate of RRF decline has been observed to be faster among HD patients compared to that of PD patients [8].

Comparison of dialysis modality revealed that intradialytic hypotension and volume depletion were most associated with the earlier onset anuria that was frequently observed in the hemodialysis population [9].

During the conservative management of patients undergoing maintenance hemodialysis [MHD], the decrease of the glomerular filtration rate [GFR] was associated with left ventricular hypertrophy [LVH]. The presence of LVH, in turn, constitutes an important independent factor of cardiovascular risk in patients with chronic kidney disease [CKD], including MHD patients. Both LVH and systolic dysfunction have major contributions to this increased risk of cardiovascular death [10].

Hypertension is a strong [particularly the systolic component] and indepen- 
dent risk factor for cardiovascular disease in the general population [11]. It occurs in an estimated 72 million people in the United States. Hypertension is the second leading cause of end-stage renal disease [ESRD] in the United States and accounts for $30 \%$ of the ESRD population. Over the past 2 decades, the prevalence and incidence of ESRD have been increasing [12].

Hypertension is both a cause and consequence of kidney disease, as the prevalence of hypertension in patients on dialysis is as high as $90 \%$. It is associated with an annual mortality of $23 \%$, mainly from cardiovascular disease. Interestingly, only a minority of patients on hemodialysis have satisfactory blood pressure control; there is better control in the peritoneal dialysis population. Reducing the morbidity and mortality associated with hypertension A range of strategies may be used and should be understood to improve control of blood pressure. To reduce the disease burden in patients with ESRD, vigorous control of hypertension is recommended [13].

In this study we are going to evaluate the impact of preserved residual renal function on prevalence and management of hypertension in patients on regular haemodialysis.

\section{Patients and Methods}

This study was conducted on sixty end stage renal disease patients who are undergoing regular hemodialysis for $>3$ months in Hemodialysis Unit at Shebin El-Koom teaching Hospital-Menoufia-Egypt, during the period from September 2015 to March 2018.

Inclusion criteria: Age $>18$ years, on haemodialysis for more than 3 months.

Exclusion criteria: Patients on diuretics.

Study groups: patients were divided into two groups: Group I: 30 Patients on regular haemodialysis who have preserved residual renal function. Group II: 30 patients on regular haemodialysis who do not have preserved residual renal function. An informed consent was taken from all subjects in the study. The study protocol was approved by the local ethical committee of the college of Medicine, Menoufia University.

Subjects were submitted to the following: Thorough history taking, Physical examination, Dialysis procedures and Calculation of residual renal function:

Methods: Containers for urine collection were given to all HD patients with verbal and written instructions to collect all produced urine over the interdialytic period. Urine volume was measured, and urine concentrations of urea nitrogen [UN] and creatinine were measured by means of conventional biochemical techniques. Urine volumes less than $100 \mathrm{~mL} / \mathrm{d}$ were discarded, and those patients were assumed to have no residual renal function. All patients had their blood pressure measured before and after 10 consecutive hemodialysis treatments. The SBP and DBP were immediately obtained before the HD session using the arm opposite the AV fistula and represented the average of the last ten HD sessions. 


\section{Statistical Analysis}

Data were fed to the computer and analyzed using IBM SPSS software package version 20.0. [Armonk, NY: IBM Corp] Qualitative data were described using number and percent. The Kolmogorov-Smirnov test was used to verify the normality of distribution Quantitative data were described using range [minimum and maximum], mean, standard deviation and median. Significance of the obtained results was judged at the $5 \%$ level.

The used tests were Chi-square test for categorical variables, to compare between different groups. Mann Whitney test, or abnormally distributed quantitative variables, to compare between two studied groups. SPSS is short for statistical package for social science, and it is used by various kinds of researchers for complex statistical data analysis.

\section{Results}

The descriptive demographic data showed that regarding mean age of studied groups, it was [50.47] and [54.97] in group 1 and 2 respectively with p value 0.205 , Regarding gender, in group 1 there were 18 male patients [60\%] and 12 female patients [40\%] and in group 2 there were 14 males [46.7\%] and 16 females [53.3\%] [Table 1].

There was no significant difference between both groups regarding age and gender.

Increasing the mean age of ESRD patients reflects the improvement of health care for such type of patients, however we still away from developed countries as mean age in United State is 61.1 years [14] and in United Kingdom [UK] is 65.9 years [15].

Distribution of the studied groups as regard Etiology of ESRD shows that the commonest cause is Diabetes mellitus (DM) with $46.7 \%$ in group 1 and $36.7 \%$ in group 2 . There was no statistically significant difference between groups regarding the cause of RF. Also $40 \%$ of group 1 were hypertensive, $66.7 \%$ of group 2 patients were hypertensive. This table shows statistically significant difference between groups regarding hypertension [Table 2].

Interdialytic weight gain mean was (1.42) in group 1 and (2.37) in group 2. There was highly statistically significant difference between both groups regarding interdialytic weight gain [Table 3].

There was no statistically significant relation between interdialytic weight gain and hypertension in group 1 patients [Table 4].

There is statistically significant relation between residual renal function and intradialytic hypertension in group 1 patients [Table 5].

Control of hypertension was achieved in $63.6 \%$ of group 1 patients by one drug, $27.3 \%$ patients by 2 drugs; however $9.1 \%$ of patients need 3 drugs to control their blood pressure, while in group 2, 40\% of patients were controlled by one drug, $45 \%$ with 2 drugs and $15 \%$ need 3 drugs to control blood pressure and there is no statistically significant difference between groups [Table 6]. 
Table 1. Comparison between group I (30 patients) and group II (30 patients) according to demographic data.

\begin{tabular}{|c|c|c|c|c|}
\hline Demographic data & $\begin{array}{c}\text { Group I } \\
\mathrm{NO}=30\end{array}$ & $\begin{array}{l}\text { Group II } \\
\mathrm{NO}=30\end{array}$ & $\mathrm{U}$ & $P$ value \\
\hline \multicolumn{5}{|l|}{ Age } \\
\hline Mean \pm SD & $50.47 \pm 13.5$ & $54.97 \pm 10.9$ & 1.26 & 0.205 \\
\hline Median & 54.00 & 59.50 & & \\
\hline Rang & $19-70$ & $23-65$ & & \\
\hline Sex & No $\%$ & No $\%$ & & \\
\hline Male & $18 \quad 60.0$ & 46.7 & 1.071 & $0.301^{\star}$ \\
\hline Female & $12 \quad 40.0$ & $16 \quad 53.3$ & & \\
\hline
\end{tabular}

Table 2. Comparison between group I [30 patients] and group II [30 patients] regarding the Etiology of ESRD and Prevalence of hypertension.

\begin{tabular}{|c|c|c|c|c|c|c|c|}
\hline & & \multicolumn{2}{|c|}{$\begin{array}{c}\text { Group I } \\
\text { NO }=30\end{array}$} & \multicolumn{2}{|c|}{$\begin{array}{l}\text { Group II } \\
\mathrm{NO}=30\end{array}$} & \multirow[t]{2}{*}{$\mathrm{x} 2$} & \multirow[t]{2}{*}{$P$ value } \\
\hline & & No & $\%$ & No & $\%$ & & \\
\hline \multirow{6}{*}{$\begin{array}{c}\text { Etiology of } \\
\text { ESRD }\end{array}$} & $\mathrm{DM}$ & 14 & 46.7 & 11 & 36.7 & \multirow{6}{*}{5.539} & \multirow{6}{*}{0.354} \\
\hline & GN & 9 & 30.00 & 4 & 13.3 & & \\
\hline & HTN & 4 & 13.3 & 9 & 30.0 & & \\
\hline & PCDK & 1 & 3.3 & 2 & 6.7 & & \\
\hline & Infection & 1 & 3.3 & 3 & 10.0 & & \\
\hline & LUPUS & 1 & 3.3 & 1 & 3.3 & & \\
\hline \multirow{2}{*}{ Hypertension } & No & 18 & 60 & 10 & 33.3 & \multirow{2}{*}{4.286} & \multirow{2}{*}{0.032} \\
\hline & Yes & 12 & 40 & 20 & 66.7 & & \\
\hline
\end{tabular}

Table 3. Comparison between group I [30 patients] and group II [30 patients] regarding interdialytic weight gain.

\begin{tabular}{ccccc}
\hline Intra-dialysis weight gain $[\mathrm{KG}]$ & $\begin{array}{c}\text { Group I } \\
\text { NO }=\mathbf{3 0}\end{array}$ & $\begin{array}{c}\text { Group II } \\
\text { NO }=30\end{array}$ & U & P value \\
\hline Mean \pm SD & $1.42 \pm 0.64$ & $2.3 \pm 0.91$ & & \\
Median & 1.50 & 2.25 & 3.952 & 0.001 \\
Rang & $1-3$ & $1-4$ & & \\
\hline
\end{tabular}

U Mann-Whitney.

Table 4. Relation between interdialytic weight gain and HTN in group I [30 patients].

\begin{tabular}{ccccc}
\hline Group I & $\begin{array}{c}\text { Hypertensive } \\
\text { NO }=20\end{array}$ & $\begin{array}{c}\text { Non hypertensive } \\
\text { NO }=18\end{array}$ & U & P value \\
\hline Interdialytic weight gain $[\mathrm{KG}]$ & & & & \\
Mean \pm SD & $1.3 \pm 0.62$ & $1.4 \pm 0.64$ & 0.218 & 0.827 \\
Median & 1.2 & 1.5 & & \\
Rang & $1-3$ & $1-3$ & & \\
\hline
\end{tabular}

U Mann-Whitney. 
Table 5. Relation between residual kidney function and intradialytic HTN in group I [30 patients].

\begin{tabular}{ccccc}
\hline & \multicolumn{2}{c}{ Intradialytic HTN } & & \\
\cline { 2 - 3 } Group I & Yes & No & P value \\
& NO $=10$ & NO $=20$ & & \\
\hline Residual kidney function $[\mathrm{ml} / \mathrm{min}]$ & & & & \\
Mean \pm SD & $9.0 \pm 5.4$ & $18.40 \pm 5.8$ & & \\
Median & 8.0 & 11.5 & & $\mathbf{0 . 0 2 8}$ \\
Rang & $5-18$ & $5-22$ & & \\
\hline
\end{tabular}

U Mann-Whitney.

Table 6. Comparison between group I [30 patients] and group II [30 patients] regarding number of antihypertensive drugs used to control hypertension.

\begin{tabular}{|c|c|c|c|c|c|c|}
\hline \multirow[t]{2}{*}{ Drug to control HTN } & \multicolumn{2}{|c|}{$\begin{array}{l}\text { Group I } \\
\mathrm{NO}=11\end{array}$} & \multicolumn{2}{|c|}{$\begin{array}{l}\text { Group II } \\
\mathrm{NO}=20\end{array}$} & \multirow[t]{2}{*}{$\mathrm{X}^{2}$} & \multirow[t]{2}{*}{$P$ value } \\
\hline & No & $\%$ & No & $\%$ & & \\
\hline Mono-drug & & 63.6 & 8 & 40.0 & \multirow{3}{*}{1.58} & \multirow{3}{*}{0.452} \\
\hline Dia-drug & 3 & 27.3 & 9 & 45.0 & & \\
\hline Triple-drug & 1 & 9.1 & 3 & 15.0 & & \\
\hline
\end{tabular}

\section{Discussion}

Our study was conducted entirely on regular HD patients, because this is the commonly available type of renal replacement therapy in Egypt; however Biesen van et al. [16] showed that RRF is preserved longer on PD type of therapy. This philosophy is usually applied for patients facing many years of dialysis, where the placement on PD may prolong the RRF and limit lifetime demands on vascular access with consideration of modality switch if the patient loses RRF and encounters problems such as hypervolemia. Using this approach, patients starting on PD and changing to HD have had improved survival compared with those starting, and remaining, on HD [16].

This study revealed that the commonest cause of ESRD is DM [diabetes mellitus] with [46.7\%] in group $1 \&$ [36.7\%] in group 2 then comes glomerulonephritis [GN] [30\%] in group 1, [13.3\%] in group 2. Hypertension causes ESRD in [13.3\%] in group 1 and [30\%] in group 2, polycystic kidney disease [3.3\%] in group $1 \&[6.7 \%]$ in group 2, chronic pyelonephritis [3.3\%] in group $1 \&[10 \%]$ in group 2, lupus nephritis [3.3\%] in both groups, that goes in agreement with the study of Tuttle KR, et al. [17] which states that Diabetes mellitus is the most common cause of chronic kidney disease in the world.

In the comparison between both groups regarding interdialytic weight gain there was highly statistically significant difference between groups which goes in agreement with Kimmel et al. [18], López-Gómez et al. [19] and Termorshuizen et al. [20] whose results states that average interdialytic weight gain in the group of patients with preserved RRF was also decreased significantly with respect to the average weight gain in the group of patients without preserved RRF, which 
clearly indicates that patients with preserved RRF have better body water volume control.

Comparison between groups regarding hypertension significant difference between groups was discovered [40\%] of group 1 patients were hypertensive while $66.7 \%$ of group 2 were hypertensive, with $p$ value [0.032], Which went in agreement with Ajanovic et al. [21] who found that In the group of patients without preserved RRF hypertension was frequent [74.4\% vs $25.6 \%$ ].

Regarding the relation between residual renal function and control of hypertension represented in the number of drugs used to maintain normal blood pressure the study shows that in group 1 [63.6\%] were controlled by one drug, [27.3\%] controlled by 2 drugs and [9.1\%] need 3 drugs to control their blood pressure. While in group 2 [40\%] controlled by one drug, [45\%] got control with 2 drugs and $15 \%$ need 3 drugs to be controlled.

In group 1 [with preserved residual renal function] there was statistically significant relation between residual renal function $[\mathrm{ml} / \mathrm{min}]$ and intradialytic hypertension. meaning that patients who have more preserved RRF are less liable for developing intradialytic hypertension that goes in the same context with Ok E, et al. [22] who states that Loss of RRF predisposes patients to poor Extra cellular volume and BP control.

\section{Conclusion}

From this study, we can conclude that preserved RRF has a significant relation with decreasing the incidence of developing hypertension in patients with ESRD on regular $\mathrm{HD}$, but the relation between residual renal function and control of hypertension is not statistically significant. And more comprehensive study is needed.

\section{Conflicts of Interest}

The authors declare no conflicts of interest regarding the publication of this paper.

\section{References}

[1] Søndergaard, H. and Juul, S. (2010) Self-Rated Health and Functioning in Patients with Chronic Renal Disease. Danish Medical Bulletin, 57, A4220.

[2] Shafi, T., Jaar, B.G., Plantinga, L.C., Fink, N.E., Sadler, J.H., Parekh, R.S., Powe, N.R. and Coresh, J. (2010) Association of Residual Urine Output with Mortality, Quality of Life, and Inflammation in Incident Hemodialysis Patients: The Choices for Healthy Outcomes in Caring for End-Stage Renal Disease (CHOICE) Study. American Journal of Kidney Diseases, 56, 348-358. https://doi.org/10.1053/j.ajkd.2010.03.020

[3] Perl, J. and Bargman, J.M. (2009) The Importance of Residual Kidney Function for Patients on Dialysis: A Critical Review. American Journal of Kidney Diseases, 53, 1068-1081. https://doi.org/10.1053/j.ajkd.2009.02.012

[4] Brener, Z.Z., Kotanko, P., Thijssen, S., Winchester, J.F. and Bergman, M. (2010) Clinical Benefit of Preserving Residual Renal Function in Dialysis Patients: An Up- 
date for Clinicians. The American Journal of the Medical Sciences, 339, 453-456. https://doi.org/10.1097/MAJ.0b013e3181cf7d5b

[5] United States Renal Data System (2015) USRDS Annual Data Report: Epidemiology of Kidney Disease in the United States. National Institutes of Health, National Institute of Diabetes and Digestive and Kidney Diseases, Bethesda

[6] Wang, A.M. and Lai, K.N. (2006) The Importance of Residual Renal Function in Dialysis Patients. Kidney International, 69, 1726-1732. https://doi.org/10.1038/sj.ki.5000382

[7] Vilar, E., Wellsted, D., Chandna, S.M., Greenwood, R.N. and Farrington, K. (2009) Residual Renal Function Improves Outcome in Incremental Haemodialysis despite Reduced Dialysis Dose. Nephrology Dialysis Transplantation, 24, 2502-2510. https://doi.org/10.1093/ndt/gfp071

[8] Perl, J., Huckvale, K., Chellar, M., John, B. and Davies, S.J. (2009) Peritoneal Protein Clearance and Not Peritoneal Membrane Transport Status Predicts Survival in a Contemporary Cohort of Peritoneal Dialysis Patients. Clinical Journal of the American Society of Nephrology, 4, 1201-1206.

[9] Davies, S.J., Phillips, L., Naish, P.F. and Russell, G.I. (2001) Peritoneal Glucose Exposure and Changes in Membrane Solute Transport with Time on Peritoneal Dialysis. American Society of Nephrology, 12, 1046-1051.

[10] Verdecchia, P., Carini, G., Circo, A., Dovellini, E., Giovannini, E., Lombardo, M., Solinas, P., Gorini, M., Maggioni, A.P. and MAVI Study Group (2001) Left ventricular Mass and Cardiovascular Morbidity in Essential Hypertension: The MAVI Study. Journal of the American College of Cardiology, 38, 1829-1835.

https://doi.org/10.1016/S0735-1097(01)01663-1

[11] Oliveria, S.A., Chen, R.S., McCarthy, B.D., Davis, C.C. and Hill, M.N. (2005) Hypertension Knowledge, Awareness, and Attitudes in a Hypertensive Population. Journal of General Internal Medicine, 20, 219-225. https://doi.org/10.1016/S0735-1097(01)01663-1

[12] Toto, R.D. (2005) Management of Hypertensive Chronic Kidney Disease: Role of Calcium Channel Blockers. The Journal of Clinical Hypertension, 7, 15-20. https://doi.org/10.1111/j.1524-6175.2004.4471.x

[13] Ram, C.V. and Fenves, A.Z. (2009) Management of Hypertension in Hemodialysis Patients. Current Hypertension Reports, 11, 292-298. https://doi.org/10.1007/s11906-009-0049-y

[14] Collins, A.J., Foley, R.N., Herzog, C., et al. (2011) US Renal Data System 2010 Annual Data Report. American Journal of Kidney Diseases, 57, e1-e526.

[15] Pruthi, R., Steenkamp, R. and Feest, T. (2013) UK Renal Registry 16th Annual Report: Chapter 8 Survival and Cause of Death of UK Adult Patients on Renal Replacement Therapy in 2012: National and Centre Specific Analyses. Nephron Clinical Practice, 125, 139-169. https://doi.org/10.1159/000360027

[16] Van Biesen, W., Vanholder, R.C., Veys, N., Dhondt, A. and Lameire, N.H. (2000) An Evaluation of an Integrative Care Approach for End-Stage Renal Disease Patients. Journal of the American Society of Nephrology, 11, 116-125.

[17] Tuttle, K.R., Bakris, G.L., Bilous, R.W., et al. (2014) Diabetic Kidney Disease: A Report from an ADA Consensus Conference. Diabetes Care, 37, 2864-2883. https://doi.org/10.2337/dc14-1296

[18] Kimmel, P.L., Varela, M.P., Peterson, R.A., Weihs, K.L., Simmens, S.J., Alleyne, S., Amarashinge, A., Mishkin, G.J., Cruz, I. and Veis, J.H. (2000) Interdialytic Weight 
Gain and Survival in Hemodialysis Patients: Effects of Duration of ESRD and Diabetes Mellitus. Kidney International, 57, 1141-1151. https://doi.org/10.1046/j.1523-1755.2000.00941.x

[19] López-Gómez, J.M., Villaverde, M., Jofre, R., Rodriguez-Benítez, P. and Pérez-García, R. (2005) Interdialytic Weight Gain as a Marker of Blood Pressure, Nutrition, and Survival in Hemodialysis Patients. Kidney International, 67, 63-68. https://doi.org/10.1111/j.1523-1755.2005.09314.x

[20] Termorshuizen, F., Dekker, F.W., Van Manen, J.G., Korevaar, J.C., Boeschoten, E.W. and Krediet, R.T. (2004) Relative Contribution of Residual Renal Function and Different Measures of Adequacy to Survival in Hemodialysis Patients: An Analysis of the Netherlands Cooperative Study on the Adequacy of Dialysis (NECOSAD)-2. Journal of the American Society of Nephrology, 15, 1061-1070. https://doi.org/10.1097/01.ASN.0000117976.29592.93

[21] Ajanovic, S., Resic, H., Masnic, F., Coric, A., Beciragic, A., Prohic, N., Dzubur, A. and Tomic, M. (2015) Association between Hypertension and Residual Renal Function in Hemodialysis Patients. BANTAO Journal, 13, 73-78. https://doi.org/10.1515/bj-2015-0016

[22] Ok, E., Levin, N.W., Asci, G., Chazot, C., Toz, H. and Ozkahya, M. (2017) Interplay of Volume, Blood Pressure, Organ Ischemia, Residual Renal Function, and Diet: Certainties and Uncertainties with Dialytic Management. Seminars in Dialysis, 30, 420-429. https://doi.org/10.1111/sdi.12612 